\title{
Дальномер на основе иттербиевого волоконного лазера с самосканированием длины волны
}

\author{
А.М. Воликова ${ }^{*}$, Н.Н. Смолянинов, И.А. Лобач, С.И. Каблуков \\ Институт автоматики и электрометрии СО РАН \\ *E-mail: anastasiya-volikova@yandex.ru
}

DOI: 10.31868/RFL2020.189-190

Лазерные дальномеры находят свое применение как для военных, так и для гражданских целей. По технике измерений различают геометрический и рефлектометрический методы. В первом методе источник и детектор разнесены друг относительно друга на определенное расстояние, а по измеренным углам можно вычислить расстояние до цели. Во втором - регистрируется время задержки между испущенным и пришедшим на фотодетектор сигналами. Последний метод также разделяют на импульсный и фазовый подходы [1]. Импульсный дальномер работают по принципу регистрации эха. В случае фазового дальномера интенсивность зондирующего излучения модулируется по гармоническому закону. Интенсивность, отраженного от объекта, излучения приобретает сдвиг фазы относительного зондирующего сигнала, которая пропорциональна временной задержке. Также известны подходы в дальнометрии с использованием лазеров со сканированием частоты. В этом случае отраженное от объекта излучение было сгенерировано в более ранний период и поэтому имеет другую частоту в сравнении с непрерывно перестраиваемым лазером. Частота биений двух сигналов пропорциональна скорости сканирования и времени задержки при прохождении света до объекта и обратно. Для этого подхода требуется относительно небольшой диапазон сканирования лазера (может составлять несколько ГГц), так как разность частот измеряется с помощью обычного фотодетектора.

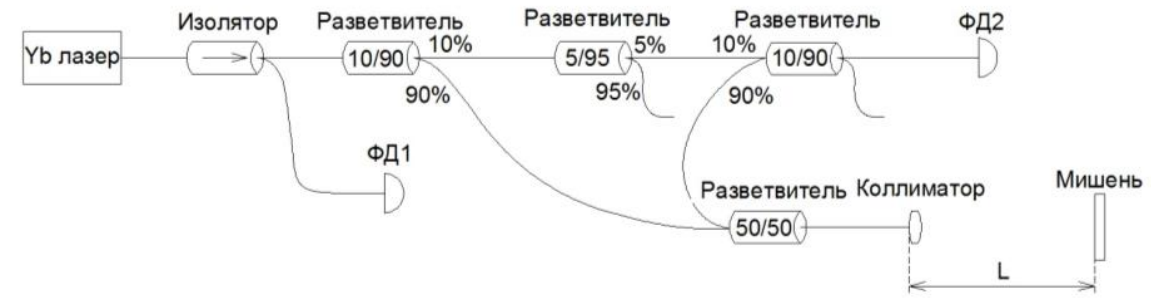

Рис. 1. Оптическая схема дальномера на основе иттербиевого волоконного лазера с самосканированием длины волны.

Лазеры с самосканированием длины волны представляют один из видов перестраиваемых лазеров, в которых процесс перестройки происходит спонтанно за счет внутренних процессов без использования специальных управляемых извне селективных элементов. В иттербиевых волоконных лазерах ширина области самосканирования может превышать 20 нм. Мы предлагаем использовать такой лазер для измерения абсолютного расстояния до удаленной мишени с помощью интерферометра Маха-Цендера. Лазер генерирует импульсное узкополосное излучение [2]. В каждом импульсе генерируется одна продольная мода. С каждым новым импульсом частота уменьшается строго на одно межмодовое расстояние. Оптическая схема предлагаемого дальномера приведена на Рис. 1. На выходе лазера установлен изолятор с дополнительным контрольным портом для нормировки мощности. Расстояние измерялось с помощью интерферометра Маха-Цендера. Интерферометр состоял из двух разветвителей 10/90. В опорное плечо вставлен дополнительный разветвитель 5/95 для уменьшения мощности, а в измерительное 
плечо - разветвитель 50/50, который выполняет функцию циркулятора. Луч на выходе из волокна коллимировался отражательным коллиматором, рассеивался на мишени и собирался коллиматром обратно в волокно интерферометра. Для устранения флуктуаций в измеряемой интерферограмме производилась нормировка выходного интерференционного сигнала с фотодетектора ФД2 поимпульсным делением на входной опорный (с ФД1). Частота осцилляций интерферограммы пропорциональна разности плеч в интерферометре. Для получения рефлектограммы к интерферограмме применяли быстрое преобразование Фурье.

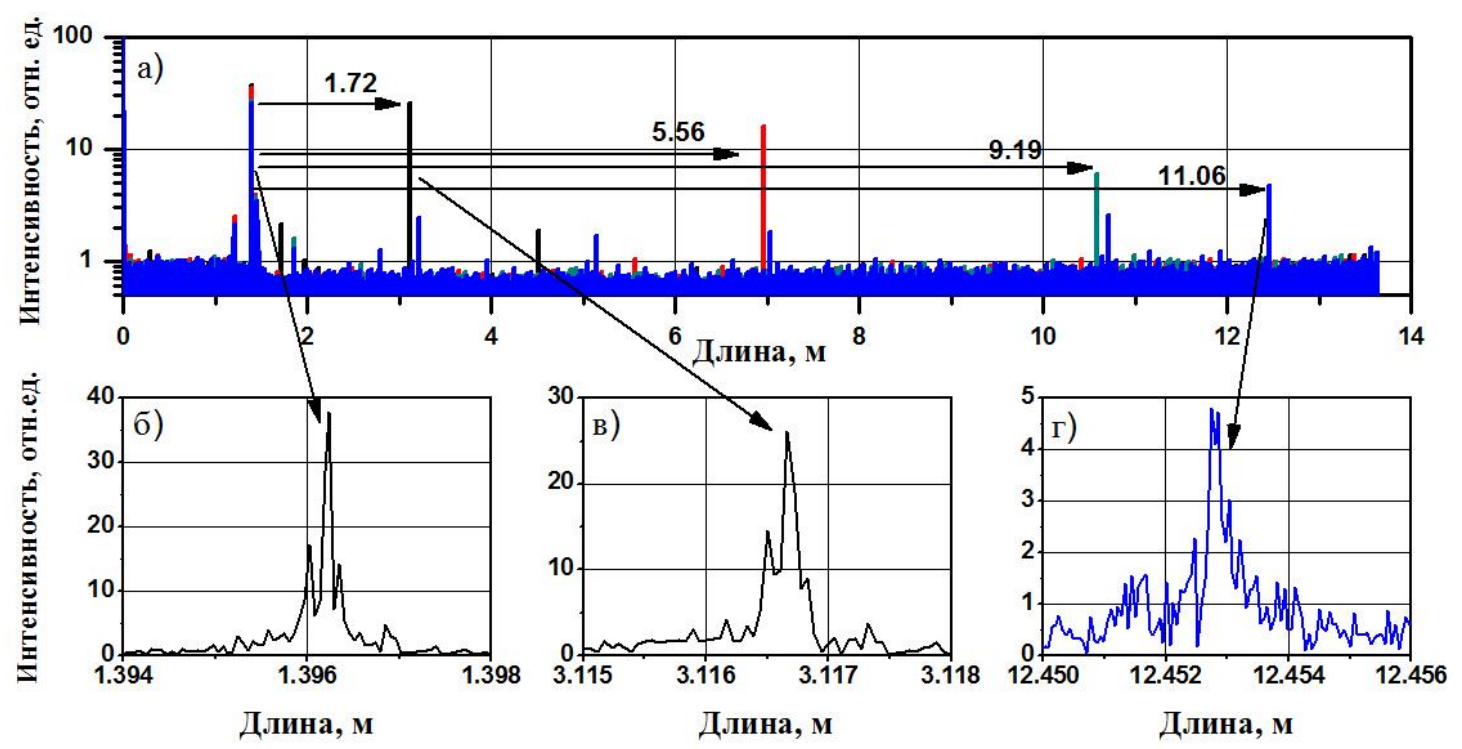

Рис. 2. а) Серия рефлектограмм для расстояний до мишени 1.72, 5.56, 9.19 и 11.06 м, б) отражение от FC/AРC коннектора, в, г) пики рассеяния от мишени, соответствующие расстояниям 1.72 и 11.06 м соответственно. На рисунке приведена оптическая длина. Геометрическая длина волокна на рефлектограмме в показатель преломления раз меньше (0.97 м).

На Рис.2а представлены примеры рефлектограмм при разных расстояниях до мишени. В эксперименте мишенью служила подвижка со шлифованной чернёной алюминиевой поверхностью. Максимальная длина, для которой можно определить расстояние до мишени, определялась межмодовой частотой лазера и составила примерно 13.6 метра. Первый пик на расстоянии 1.4 м соответствует отражению от FC/APC коннектора, вставленный в коллиматор. Расстояния от коннектора до мишени указаны рядом со стрелками на Рис. 2а. Для увеличения расстояния до мишени использовали дополнительные поворотные зеркала (не показаны на рисунке). Можно заметить, что с увеличением расстояния от коннектора до мишени наблюдается уменьшение амплитуды пика рассеяния и увеличение его ширины от 0.16 мм до 0.4 мм на расстоянии 1.72 и 11.06 м соответственно. Такое поведение, вероятно, связано с дрожанием оптических элементов и неоднородностью рассеивающей поверхности. Нами экспериментально продемонстрирована возможность измерения расстояний до $\sim 11$ м с точностью $\sim 0.5$ мм. Более подробное описание схемы дальномера и полученных результатов будут представлены в докладе.

Исследование выполнено в рамках гранта Российского научного фонда (проект № 18-12-00243).

\section{Литература}

[1] Л.А. Аснис, В.П. Васильев и др. Лазерная дальнометрия.- М.: Радио и связь, 1995.- 256.

[2] I.A. Lobach, S.I. Kablukov et al, Laser Phys. Lett. 11, 045103 (2014). 